\title{
Nucleic Acids in Atypical Conditions
}

\section{Yuri Pivovarenko}

Research and Training Center 'Physical and Chemical Materials Science' under Kyiv Taras Shevchenko University and NAS of Ukraine, Kiev, Ukraine

\section{Email address: \\ y.pivovarenko@gmail.com}

\section{To cite this article:}

Yuri Pivovarenko. Nucleic Acids in Atypical Conditions. European Journal of Biophysics. Vol. 3, No. 1, 2015, pp. 5-9.

doi: $10.11648 /$ j.ejb.20150301.12

\begin{abstract}
Here we describe some properties of nucleic acids, which observed in 'atypical" experiments. So, we show that physical and chemical properties of nucleic acids depend on dissolved gases. We show particularly that thermal hyperchromism of DNA depends on dissolved oxygen and (or) air. It has been showed most importantly the thermal hyperchromism does not observe for DNA degassed solutions. Here we also demonstrate the difference between some chemical properties of nucleic acids in degassed solutions and in solutions saturated with hydrogen or oxygen. We illustrate too the difference between physical and chemical properties of nucleic acids in the homogenous and gradient-containing solutions; the last case we offer as approximation of the conditions, in which the nucleic acids exist in vivo.
\end{abstract}

Keywords: DNA, RNA, DNA Hyperchromism, DNA Melting, Phenazine

\section{Introduction}

In most cases don't pay attention to the presence of gases in the solutions of nucleic acids (NA). Accordingly, does not take into account the effect of these gases on physicochemical properties of aqueous NA, in [1]. In particular, the effect of dissolved air (and, obviously, oxygen) on the thermal stability of DNA in the melting experiments is mostly ignored. It is not acceptable, because:

1. The typical DNA working solutions are oxygen or air containing;

2. The content of these gases in DNA working solutions is very variable;

3. The oxygenation of DNA solutions accompany to their UV hyperchromism, in [2,3].

Separately need to say about hydrogen, because its donors (glucose, fats, etc.) and carriers (NADH, FAD, etc.) widespread in the cytoplasm, nucleus and mitochondria. Need to taken also into account that intestinal gases contain $75 \%$ hydrogen and, as rule, don't contain oxygen.

For these reasons, we finished that the influence dissolved gases on the physical and chemical properties of NA need to study.

Discretely need to discuss the selection of buffers. Analyzing scientific literature can to conclude that buffers, using by the study of NA, are various, in [1]. So, researchers, which studied the interaction between NA and aromatic dyes, used solutions with different $\mathrm{pH}$ (from 5.5 to 8 ) and ionic strengths. In particular, were used: $0,2 \mathrm{M}$ acetate buffer, $\mathrm{pH}$ 5, in [4], MES-buffers of different concentrations, $\mathrm{pH} \mathrm{6,2,} \mathrm{in}$ [5-6], 0,01 M phosphate

buffer, $\mathrm{pH} 7$, in [7-8], 0,1 $\mathrm{M}$ deuterated phosphate buffer, pD 6,6, in [9], 0,1 мM Tris-HCl-buffer, $\mathrm{pH} \mathrm{8,} \mathrm{in} \mathrm{[10],} 1 \mathrm{mM}$

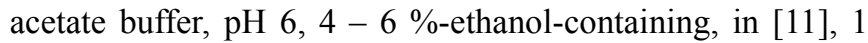
$\mathrm{mM}$ acetate buffer, $\mathrm{pH} \mathrm{7,} \mathrm{in} \mathrm{[12],} 1 \mathrm{mM}$ Na-cacodylate buffer, $\mathrm{pH}$ 7, 0,5 mM Na2EDTA containing, in [13], etc.

It should be noted that the selection of buffer authors have traditionally not motivated. As a result; there were obtained the numerous results that cannot be compared, because the state and properties of aqueous NA, as known, strongly depend from their environment, that is, from the composition of NA solutions.

The most part the physical and chemical properties of NA in the homogenous solutions are researching, in [1,14]. It is not good enough, because in vivo NA exist mainly in the gradient-containing systems. In particular, the concentration of Nat-ions in the nuclei of somatic cells mammalians 10 times more than in cytoplasm, in [15-19]; consequently, in vivo DNA and RNA of mammalians exist in the systems containing two phases with different concentrations of $\mathrm{Na}+$ ions. 


\section{Main Body}

At first we supposed that physical and chemical properties of NA have been depended on dissolved gases. To verify this supposition we studied influence of dissolved gases both on thermal UV hyperchromism of DNA and on interactions between NA and phenazine.

At second we supposed that properties of nucleic acids in the homogenous and gradient containing solutions have a difference. This supposition was also verified experimentally.

\section{Materials and Methods}

DNA was purchased from Fluka (Switzerland).

DNA was dissolved in $10^{-3} \mathrm{M}$ citric buffer, $\mathrm{pH} 7$, in [1].

To degas, DNA solutions $\left(20^{\circ} \mathrm{C}\right)$ were stored at pressure $~$ $13 \mathrm{mmHg}$ during one hour.

To gases saturation, DNA solutions $\left(20^{\circ} \mathrm{C}\right)$ were bubbled with gases; gases were supplied at 1,05 atmospheric pressure, for half an hour, in [2,3].

The water with exactly air contain we obtained by mixing exactly volumes de-aerated and fresh distillated water. (The air-contain in the de-aerated water we received at a $0 \%$ and in the fresh distillated water - at a $100 \%$.) For example, the water with $40 \%$ to air was obtained by mixing of $40 \mathrm{ml}$ fresh distillated water and of $60 \mathrm{ml}$ de-aerated water.

Thermal melting of DNA was organized in correspondence with [20,21].

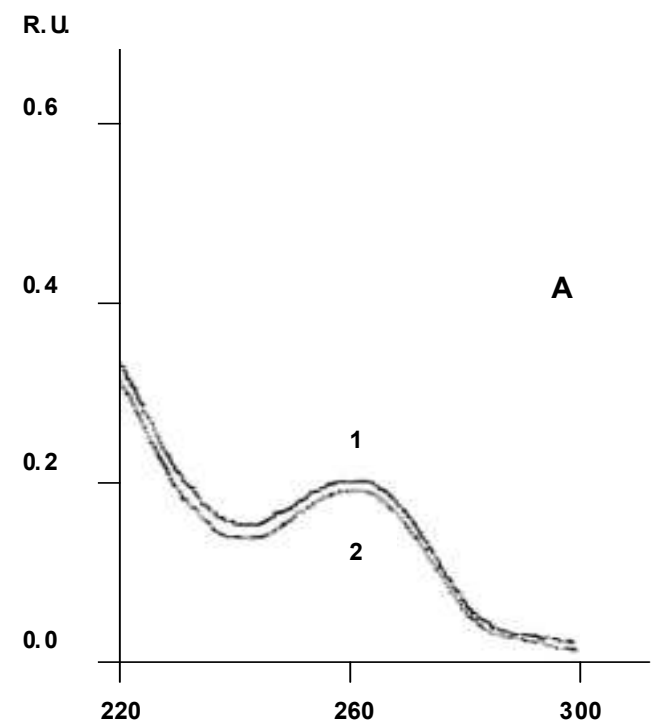

The magnitudes of thermal hyperchromism of DNA solutions $\mathrm{h}(\%)$ were determined by the formula:

$$
\mathrm{h}(\%)=\left[\mathrm{A}_{260}\left(95^{\circ} \mathrm{C}\right)-\mathrm{A}_{260}\left(20^{\circ} \mathrm{C}\right) / \mathrm{A}_{260}\left(20^{\circ} \mathrm{C}\right)\right] \cdot 100 \%,
$$

where: $\mathrm{A}_{260}\left(95^{\circ} \mathrm{C}\right)$ - absorbance of DNA solution at $95^{\circ} \mathrm{C}$; $\mathrm{A}_{260}\left(20^{\circ} \mathrm{C}\right)-$ absorbance of DNA solution at $20^{\circ} \mathrm{C}$.

UV absorption spectra were recorded using Specord UV VIS (Carl Zeiss Jena, Germany).

$\mathrm{A}_{260}$ of DNA solutions were recorded using CФ-46 (LOMO, Russia).

To demonstrate the difference between properties of NA in homogenous and heterogeneous solutions, we used 2,7dimethoxi-10-N-oxyd-5-methylphenaziniumperchlorate. This dye altered the color in the interaction with NA (fig. 2,3).

\section{Results}

\subsection{Influence Dissolved Air and Oxygen on Uv Absorbance Heated DNA Water Solutions}

\subsubsection{DNA Thermal Hyperchromism in Solutions with Different Content of Oxygen}

We found that heating the DNA degassed solutions does not alter their absorption in the range $220-300 \mathrm{~nm}$ (fig. 1A). It was also found that heating the saturated with oxygen DNA solutions follows a noticeable UV hyperchromism: $100-$ $150 \%$ (fig. 1B).

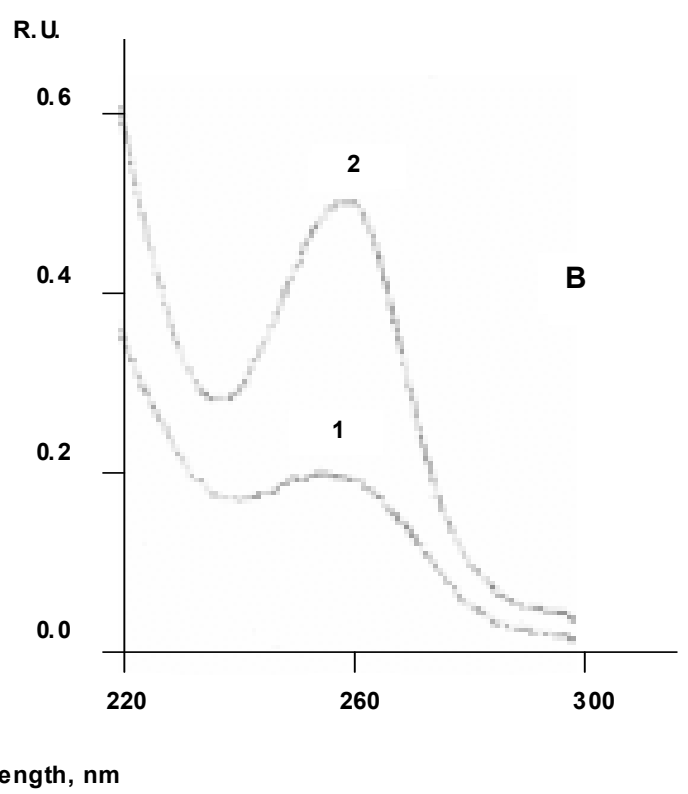

Fig. 1. A. UV absorption spectra of DNA dissolved in an oxygen-free buffer: 1 - at $20^{\circ} \mathrm{C} ; 2-$ at $95^{\circ} \mathrm{C}$. B. UV absorption spectra of DNA, dissolved in a buffer saturated with oxygen: $1-$ at $20^{\circ} \mathrm{C} ; 2-$ at $95^{\circ} \mathrm{C}$.

The UV absorption spectra were obtained for DNA solutions by simply recording at temperatures below (1) and above (2) its melting temperature $\left(\mathrm{Tm} \sim 75^{\circ} \mathrm{C}\right)$. The spectra were not processed (!).

\subsubsection{DNA Thermal Hyperchromism in Solutions with Different Content of Air}

As we expected the DNA thermal hyperchromism depends also on dissolved air (table 1). 
Table 1. The thermal hyperchromism of DNA solution with different air contain.

\begin{tabular}{ccc}
\hline The air content in DNA solution, \% & The thermal hyperchromism of DNA solution, \% \\
\hline 0 & 20 & 0 \\
40 & $12-9$ \\
60 & $14-18$ \\
80 & $24-28$ \\
100 & $38-43$ & 48 \\
\hline
\end{tabular}

Thus, we showed that:

UV thermal hyperchromism of DNA depend on dissolved oxygen and (or) air;

UV thermal hyperchromism of DNA has been observed only for the oxygen or air containing DNA solutions.

Since the UV thermal hyperchromism of DNA solutions reflects the conformational change of DNA, particularly a disruption of base-stacking interactions, in [1,21], can to declare that in oxygen-free solutions DNA is thermo-stabile (fig. 1A) and in oxygen-containing solutions DNA is thermolabile (fig. 1B).

\subsection{The Influence Dissolved Gases on the Interaction Between NA and Cationic Phenazines}

The interaction between NA and phenazine natural or synthetic origin are exploring a long time, in [11-13]. However, the effects of dissolved gases on such interactions have traditionally not take into account. This is strange, because the existing hypotheses imply such an impact, in $[22,23]$. Implying such an impact, we found the following relationship (table 2), in [24].

Table 2. The influence of hydrogen and oxygen on interaction between $N A$ and cationic phenazine- $N$-oxides.

\begin{tabular}{cccc}
\hline Dissolved gases & NA & Interaction between NAand phenazine-N-oxides & Interaction time, min. \\
\hline $\mathrm{H}_{2}$ & DNA & + & + \\
$\mathrm{H}_{2}$ & RNA & - & 0 \\
$\mathrm{O}_{2}$ & DNA & - & $\infty$ \\
$\mathrm{O}_{2}$ & RNA & + & $\infty$ \\
after evacuation & DNA & + & $\sim 0$ \\
after evacuation & RNA & $20-40$ \\
\hline
\end{tabular}

Thus, we established that the dissolved gases influence both on the physical and chemical properties of aqueous NA. Based observed dependence can to particularly assume that the properties of the NA from cells of the lung and, for example, intestinemay differ significantly.

In our view, these spectral effects can reflect a DNA modification by ROS, which appears during the heating of DNA solutions.

\subsection{NA in Gradient-Containing Solutions}

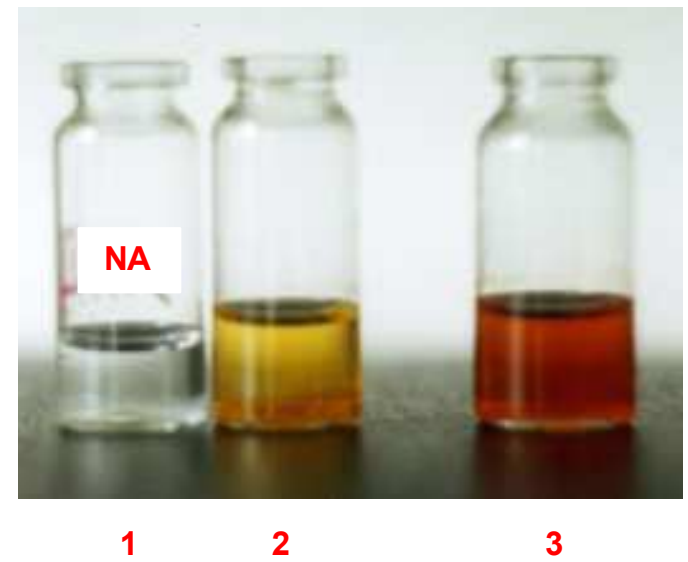

Fig. 2. In presence of colorless $N A$ (1) the yellow 2,7-dimethoxi-10-N-oxyd5-methylphenaziniumperchlorate (2) has colored in red (3). This reaction is reversible: at $[\mathrm{NaCl}] \geq 0,2 \mathrm{M}$ the red color solution, containing the products of interaction between phenazine and NA (3), changes into yellow (2).
It is known that interactions between cationic phenazines and NA did not occur in homogenous solutions with $\left[\mathrm{Na}^{+}\right] \geq$ $0,2 \mathrm{M}$, in [11]. We observed this dependence on concentration of $\mathrm{Na}^{+}$-ions for 2,7-dimethoxi-10-N-oxyd-5methylphenaziniumperchlorate too (fig. 2).

However, in the solutions, containing the gradient $(0,1 \mathrm{M} / 1,0 \mathrm{M})$ of sodium salt $\left(\mathrm{NaCl}\right.$ or $\left.\mathrm{NaH}_{2} \mathrm{PO}_{4}\right)$, DNA and 2,7-dimethoxi-10-N-oxyd-5-methylphenaziniumperchlorate interact in the phase with $1,0 \mathrm{M}$ of salt and did not interact in the phase with $0,1 \mathrm{M}$ of salt (fig. 3, left). Conversely, in these gradient-containing solutions RNA and selected dye interact in the phase with $0,1 \mathrm{M}$ salt and did not interact in the phase with 1,0M salt (fig. 3, right).

Need to say that after their homogenization, other gradient-containing solutions recovered the yellow color in the full volume.

One more chance to watch the difference between the properties of NA in the homogenous and heterogenous solutions was obtained by us in using $\mathrm{HCl}$ solutions. Near the start we observed that NA and cationic phenazine-N-oxides does not interact in the homogeneous solutions with $\mathrm{pH} \geq 5$ $\left(10^{-5} \mathrm{M}\right)$, in [22]. In a short time we found that in gradientcontaining solutions of $\mathrm{HCl}(0,01 \mathrm{M} / 0,1 \mathrm{M}$ or $0,1 \mathrm{M} / 1,0 \mathrm{M})$ DNA and cationic phenazine-N-oxides interact in the phases with high concentrations of acid and did not interact in the phases with low concentrations of acid. We also found that RNA and cationic phenazine-N-oxides interact in the phases with low concentrations $\mathrm{HCl}$ and did not interact in the phases with high concentrations of acid. 
Thus, we found that interactions of NA in the homogeneous and heterogeneous solutions have a difference. In this connection, need to repeat again: we used the gradient-containing solutions as an approximation to the native conditions of existence NA.

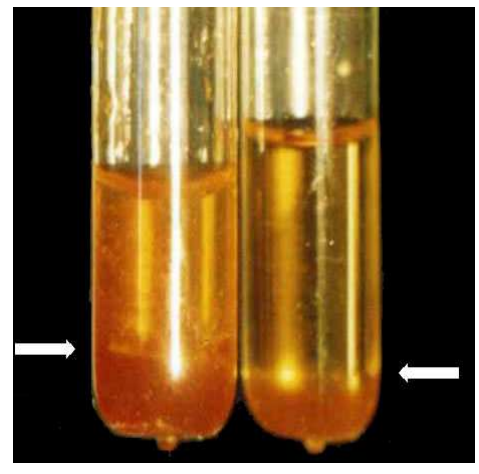

DNA

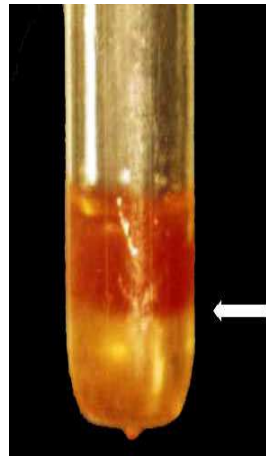

RNA
The arrows are pointing at the border between the phases with different concentrations sodium salt

Fig. 3. In the solutions, containing the gradient $(0,1 M / 1,0 M)$ of sodium salts, the DNA interacts with 2,7-dimethoxi-10-N-oxyd-5-methylphenazinium perchlorate in the lower phase with 1,0M of salt (left) and RNA-in the higher phase with 0,1M of salt (right).

\section{Conclusions}

Both physical and chemical properties of aqueous NA depend on gases dissolved in solution of NA.

The properties of NA, dissolved in homogenous and gradient-containing solutions may differ significantly. Therefore, in studying the properties of NA should be used as homogenous and heterogeneous solutions; last - as modeling natural surroundings NA.

Bringing the heterogeneous composition of the NA working solutions to their natural environment, we can more fully explore their properties in vivo.

\section{References}

[1] Saenger, W. (1993) Principles of nucleic acid structure. New York Berlin Heidelberg Tokyo: Springer-Verlag.

[2] Doshi, R., Day, P. J. R., and Tirelli, N. (2009) Dissolved oxygen alteration of the spectrophotometric analysis and quantification of nucleic acid solutions. Biochemical Society Transactions, 37(2), 466-470.

[3] Doshi, R., Day, P.J.R., Carampin, P., Blanch, E., Statford, I.J. and Tirelli, N. (2010) Spectrophotometric analysis of nucleic acids: oxygenation-dependant hyperchromism of DNA. Anal. Bioanal. Chem., 396, 2331-2339.

[4] Le Pecq, J.-B., Le Bret, M., Barbet, J. and Roques B. (1975) DNA polyintercalating drugs: DNA binding of diacridine derivates. Proc. National Academy Science USA. 72( 8), 2915-2919.
[5] Tanious, F.A., Yen, Sh.-F. and Wilson, W.D. (1991) Kinetic and Equilibrium Analysis of a Threading Intercalation Mode: DNA Sequence ad Ion Effects. Biochemistry 30(7), 18131819.

[6] Yen, S.-F., Gabbay, E.J. and Wilson W.D. (1982) Interaction of Aromatic Imides with Deoxyribonucleic Acid. Spectrophotometric and Viscometric Studies. Biochemistry. 21(9), 2070-2076.

[7] Wilson, W.D., Tanious, F.A., Barton, H.J., Jones, R.L., Fox, K., Wydra, R.L. and Strekowxki, L. (1990) DNA Sequence Dependent Binding Mades of 4',6-Diamidino-2-phenylindol (DAPI). Biochemistry. 29(36),.8452-8461.

[8] Kastrup, R.V., Jong, M.A. and Krugh, Th.R. (1978) Ethidium Bromide Complexes with Self-Complementary Deoxyribonucletides. Demonstration and Discussion of Sequence Preferences in the Interactive Binding of Ethidium Bromide. Biochemistry. 17(23), 4855-4865.

[9] Veselkov, A.N., Devis, D., Dymant, L.N. and Parkes H. (1991) Study of the interaction proflavine with deoxytetraribonucleoside triphosphate 5 -d(ApCpGpT) by one- and two- dimensional IH-NMR. Byopolymers and cell. $7(6), 5-15$.

[10] Radzevilova, O.P., Nikitina, V.V., Fedotova, O.V. Ratushnaja, E.V. and Borodulin, V.B. (2000) Interaction of thiapirillium salts with DNA. Molecular biology. 34(1) 95-100.

[11] Hollstein, U., and Van Gemert, R.Y.jr. (1971) Interaction of phenazines with polydeoxyribonucleotides. Biochemistry, 10(3), 497-504.

[12] Blagoj, Yu.P., Zozulja, V.N., Voloshin, I.M., Makitruk, V.L., Shalamai, A.S. and Sherbakova, A.S. (1997) Investigation of the interaction of phenazine derivates with DNA by polarized fluorescence. Byopolymers and cell..13(1), 22-29.

[13] Moroshkina, E.E. and Safjannikova, M.G. (1999) Interaction of DNA with phenazine derivates. Biophysics. 44(3), 425429.

[14] Long, E.C. and Barton, J.K. (1990) On demonstrating DNA interaction. Acc. Chem. Res. 23(9), 273-279.

[15] Harris, G. (1973) Nuclei and cytoplasm. Moscow: Mir.

[16] Biochemie ABC. (1976) Leipzig: VEB F.A. Brockhaus Verlag.

[17] Moore, R.D. and Morrill, G.A. (1976) A possible mechanism for concentrating sodium and potassium in the cell nucleus, Biophys. Journ. 16, 527-533.

[18] Hooper, G. and Dick, D.A.T. (1976) Nonuniform distribution of sodium in the rat hepatocyte. Journ. of General Physiology. $67,469-474$.

[19] Oberleihtner, H., Wunsch, S. and Schneider, S. (1992) Patchy accumulation of apical $\mathrm{Na}+$ transporters allows cross talk between extracellular space and cell nucleus. Proc. Nat. Acad. Sci. USA. 89, 241-245.

[20] Marmur, J. and Doty, P. (1962) Determination of the base composition of deoxyribonucleic acid from its thermal denaturation temperature. J. Mol. Biol., 5, 109-118.

[21] Mergny, J.-L., Li, J., Lacroix, L., Amrane, S. and Chaires, J. B. (2005) Thermal difference spectra: a specific signature for nucleic acid structures. Nucleic Acids Res., 33(16), 1-6. 
[22] Nagai, K.and Hecht, S.M. (1991) Site-specific Cleavage by Antisense Oligonucleotides Covalently Linked to Phenazine Di-N-oxide. J.B.C. 266(35), $23994-24002$.

[23] Nagai, K., Carter, B.J., Xu, J. and Hecht, S.M. (1991) DNA Cleavage by Oxygen Radicals Produced in the Absence of Metal Ions or Light. J. Am. Chem. Soc. 113, 5099- 5100.
[24] Pivovarenko, Y.V., Shablykin, O.V. and Vasiljev A.N. (2012) The nature of interactions between cationic phenazine-Noxide and DNA. Medical chemistry (Ukr. Ed.), 3, 20-24. 